GSA Data Repository 2018094

Urlaub, M., Geersen, J., Krastel, S., and Schwenk, T., 2018, Diatom ooze: Crucial for the generation of submarine mega-slides?: Geology, https://doi.org/10.1130/G39892.1.

\title{
Methodology
}

\section{Acoustic data}

Multibeam bathymetric data was collected during cruise MSM11/2 in 2009 with the hull-mounted Kongsberg Simrad symstem EM120. Processing was carried out with open source software MBSystem and Fledermaus Pro (QPS) to create a grid with $50 \mathrm{~m}$ resolution. During the same leg 2D highresolution multichannel seismic data were acquired using a GI Gun with $2 \times 1.71$ chamber volume (main frequencies between 100 and $200 \mathrm{~Hz}$ ) and a $500 \mathrm{~m}$ long analogue streamer hosting 80 channels. Seismic data processing was carried out with VISTA (Schlumberger) and included binning with $5 \mathrm{~m}$ size, trace editing, NMO correction and stacking as well as migration. The data is capable of resolving layers with thickness as low as $7 \mathrm{~m}$.

\section{Core-seismic integration}

We calculate the synthetic seismogram for ODP site 658 based on densities determined from GammaRay-Attenuation (GRA) and a constant p-wave velocity of $1500 \mathrm{~m} / \mathrm{s}$. Due to expansion of free gas in the sediment during core recovery reliable measurements of p-wave velocity are only available for the upper $10 \mathrm{~m}$ of the core (Ruddiman et al., 1988). However, velocity values normally scatter around a mean trend and variations in marine surface sediments do not exceed $5 \%$, whereas density variations are much higher $(>20 \%)$ within these sediments (e.g. Breitzke, 2000). Velocity data are thus less important for the calculation of reflection coefficients in this specific environment. Therefore, an initial constant $\mathrm{p}$-wave velocity of $1500 \mathrm{~m} / \mathrm{s}$ was used for the whole length of the core.

GRA density values are available for ODP cores 658A, B and C at an interval of about $0.6 \mathrm{~cm}$ including several gaps of up to a few meters. Although core A represents the longest record, values for the upper $165 \mathrm{~m}$ were taken from core B as it contains less and smaller gaps. Problems with GRA density measurements occur where the core liner is not entirely filled with sediment or where there is gas expanding in the sediment. In situ this gas was most likely dissolved in the pore water as the high resolution seismic data does not show any evidence for free gas. Already 1-3\% of free gas would reduce the P-wave velocity significantly enough to create a bright spot or blanking in the seismic data (considering the high frequencies of our data around $100 \mathrm{~Hz}$ ) (e.g. Singh et al., 19930 or Minshull et al., 1994). Hence to avoid density values affected by free gas (and thus conditions that are not representative to those in the seafloor) the density data is filtered to eliminate values lower than 1.025 $\mathrm{g} / \mathrm{cm}^{3}$, equal to the density of seawater (a lower value may only occur if gas is present in the pore space). We also apply a high-cut filter for values larger than $2.7 \mathrm{~g} / \mathrm{cm}^{3}$ (representing the density of clay or silt particles). Furthermore, the central value of a running average of 300 data points is compared to the mean of the data window. For differences greater than $0.25 \mathrm{~g} / \mathrm{cm}^{3}$ the value is deleted. We then 
calculate standard deviations for a moving 50 points window. Each value is compared to the mean of the 50 neighboring points and if the difference is larger than twice the standard deviation for the window it is eliminated. The filtering of GRA - density lead to a reduction of data points from 38516 to 33165 values. Filtering also caused gaps in the density data in some locations (e.g. between 97 and 100 mbsf and 209 and $212 \mathrm{mbsf}$ ). In order to avoid artificial reflectors produced by these data gaps we linearly interpolated to the next density value. The filtered and interpolated data was finally used for the calculation of a synthetic seismogram. As the part below $275 \mathrm{~m}$ is mainly represented by two large gaps, density data was only used above this depth. Finally, a smoothing of the density record was achieved by the use of a $10 \mathrm{~cm}$ running average. To avoid unrealistic reflection coefficients the data was linearly interpolated at places where gaps in the final density record occurred.

Reflection coefficients are calculated from the density values and constant velocity and convolved with a wavelet, which approximates the seismic signal observed in the field. As a source wavelet a standard Ricker wavelet (Ricker, 1953) was preferred over a wavelet extracted from seismic traces near the borehole. The synthetic wavelet appears smoother than the recorded one and has proven to be more useful for a visual correlation of measured and synthetic data. The wavelet contains a frequency of $100 \mathrm{~Hz}$ corresponding to the dominant frequency of the GI-gun. The sampling rate is $250 \mu$ shich is equivalent to the seismic profile. For the core-seismic integration we use the SynPAK module in the IHS Kingdom ${ }^{\circledR}$ software. The synthetic seismogram is shifted, stretched or squeezed to match the nearby seismic survey traces and the interval velocities are adapted correspondingly. The software recalculates the synthetic using the updated velocity profile. During stretching and squeezing great care was taken that the updated velocities are in a reasonable range for marine sediments $(1.2-4 \mathrm{~m} / \mathrm{s}$, Press 1966). 
TABLE DR1 High amplitude reflectors, glide planes, and post-failure reflectors providing minimum slide ages identified in the seismic line and tied in to ODP core 658 as a result of core-seismic integration. TWT is two-way-traveltime of individual reflectors at the borehole. We use the age model by Tiedemann (1991).

\begin{tabular}{lccc}
$\begin{array}{r}\text { Seismic } \\
\text { horizon }\end{array}$ & $\begin{array}{c}\text { TWT } \\
(\mathrm{s})\end{array}$ & $\begin{array}{c}\text { Core depth } \\
(\mathrm{m})\end{array}$ & $\begin{array}{c}\text { Age } \\
(\mathrm{ka})\end{array}$ \\
\hline \hline $\mathrm{H} 01$ & 3.029 & 7 & 50 \\
$\mathrm{H} 02$ & 3.046 & 20 & 149 \\
$\mathrm{H} 03$ & 3.065 & 35 & 247 \\
$\mathrm{H} 04$ & 3.088 & 51 & 342 \\
$\mathrm{H} 05$ & 3.107 & 66 & 434 \\
$\mathrm{H} 06$ & 3.128 & 83 & 563 \\
$\mathrm{H} 07$ & 3.174 & 119 & 1800 \\
$\mathrm{H} 08$ & 3.244 & 182 & 2500 \\
$\mathrm{H} 09$ & 3.308 & 234 & 2960 \\
\hline GP $_{\text {MIN }}$ & 3.112 & 69 & 434 \\
GP $_{\text {MAJ }}$ & 3.151 & 100 & 1573 \\
GP $_{\text {BUR }}$ & 3.248 & 183 & 2500 \\
\hline Post $_{\text {MIN }}$ & 3.046 & 20 & 149 \\
Post $_{\text {MAJ }}$ & 3.151 & 100 & 731 \\
Post $_{\text {BUR }}$ & 3.215 & 154 & 2300 \\
\hline
\end{tabular}




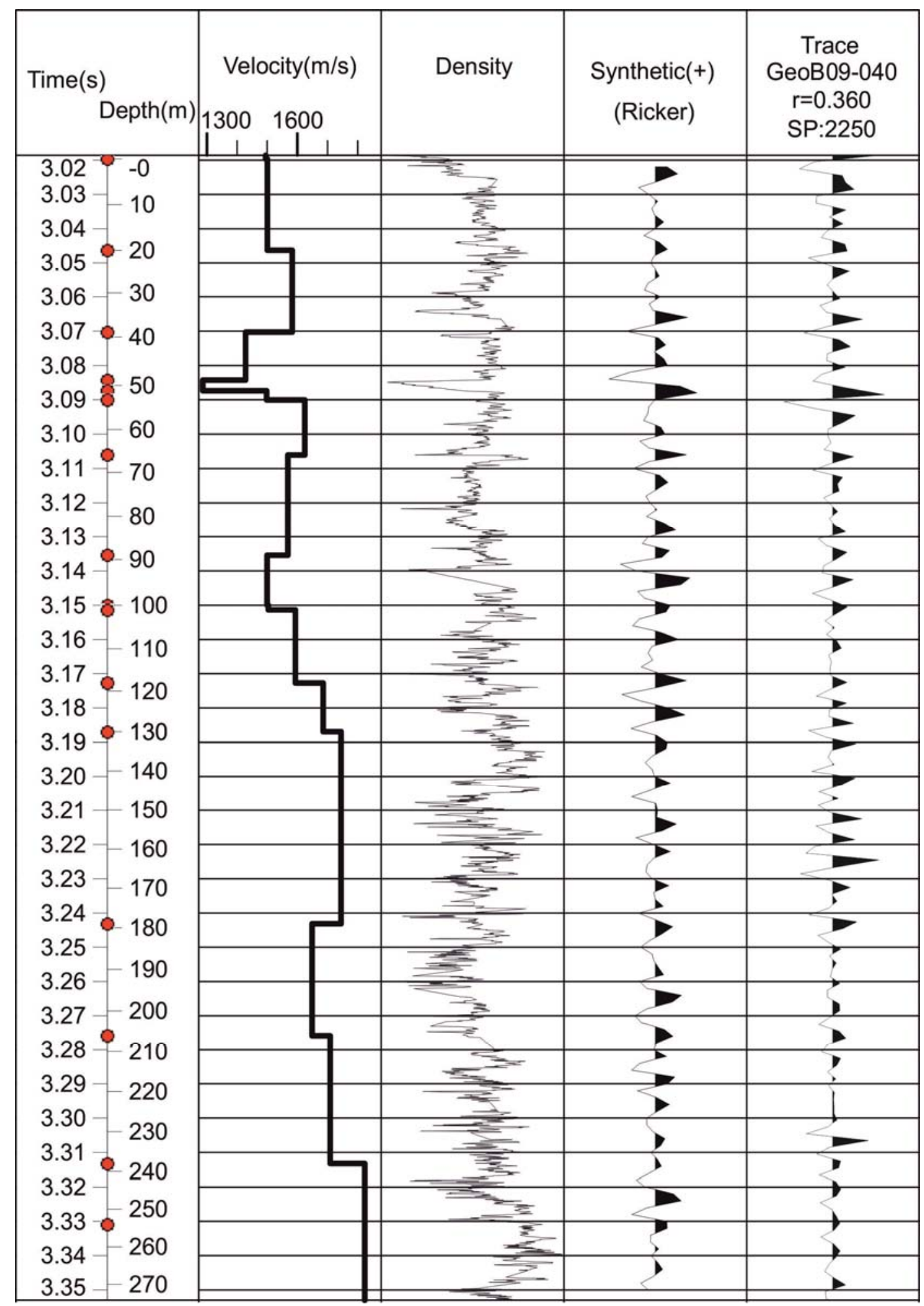

Figure DR1: Core seismic integration correlation panel. The synthetic seismogram was shifted, stretched or squeezed to match the nearby seismic survey traces and the interval velocities are adapted correspondingly.The synthetic seismogram is recalculated using the new velocity profile after each adjustment. 


\section{References}

Breitzke, M. (2000). Acoustic and elastic characterization of marine sediments by analysis, modeling, and inversion of ultrasonic P wave transmission seismograms. Journal of Geophysical Research: Solid Earth, 105(B9), 21411-21430.

Minshull, T.A., Singh, S., Westbrook, G.K. (1994). Seismic velocity structure at a gas hydrate reflector, offshore western Colombia, from full waveform inversion. Journal of Geophysical Research: Solide Earth, 99(B3), 4715-4743.

Press, F. (1966). Section 9: Seismic velocities. Geological Society of America Memoirs, 97, 195-218. Ricker, N. (1953). Wavelet contraction, wavelet expansion, and the control of seismic resolution. Geophysics, 18(4), 769-792.

Ruddiman, W., Sarnthein, M., Baldauf, J., et al., 1988. Proc. ODP, Init. Repts., 108: College Station, TX (Ocean Drilling Program).

Singh, S., Minshull, T.A., Spence, G.D. (1993). Velocity Structure of a Gas Hydrate Reflector. Science, 260, 5105, 204-207.

Tiedemann, R., 1991. Acht Millionene Jahre Klimageschichte von Nordwest Afrika und PaläoOzeanographie des angrenzenden Atlantik: Hochauflösende Zeitreihen von ODP-Sites 658-661. [Ph.D. thesis]: University of Kiel, Germany, 127 p.

\section{Additional figures}

Figure DR2: Seismic line GeoB09-040 uninterpreted and at high resolution.

Figure DR3: Seismic line GeoB03-017 downslope that crosses line GeoB09-040 at a right angle at ODP Site 658.

Figure DR4: High resolution seismic lines showing high amplitude reflectors that are typical for the shallow sediments on the continental slope of Northwest Africa and that coincide with landslide scars for A) Sahara Slide, B) Mauritania Slide, and C) Dakar Slide. 







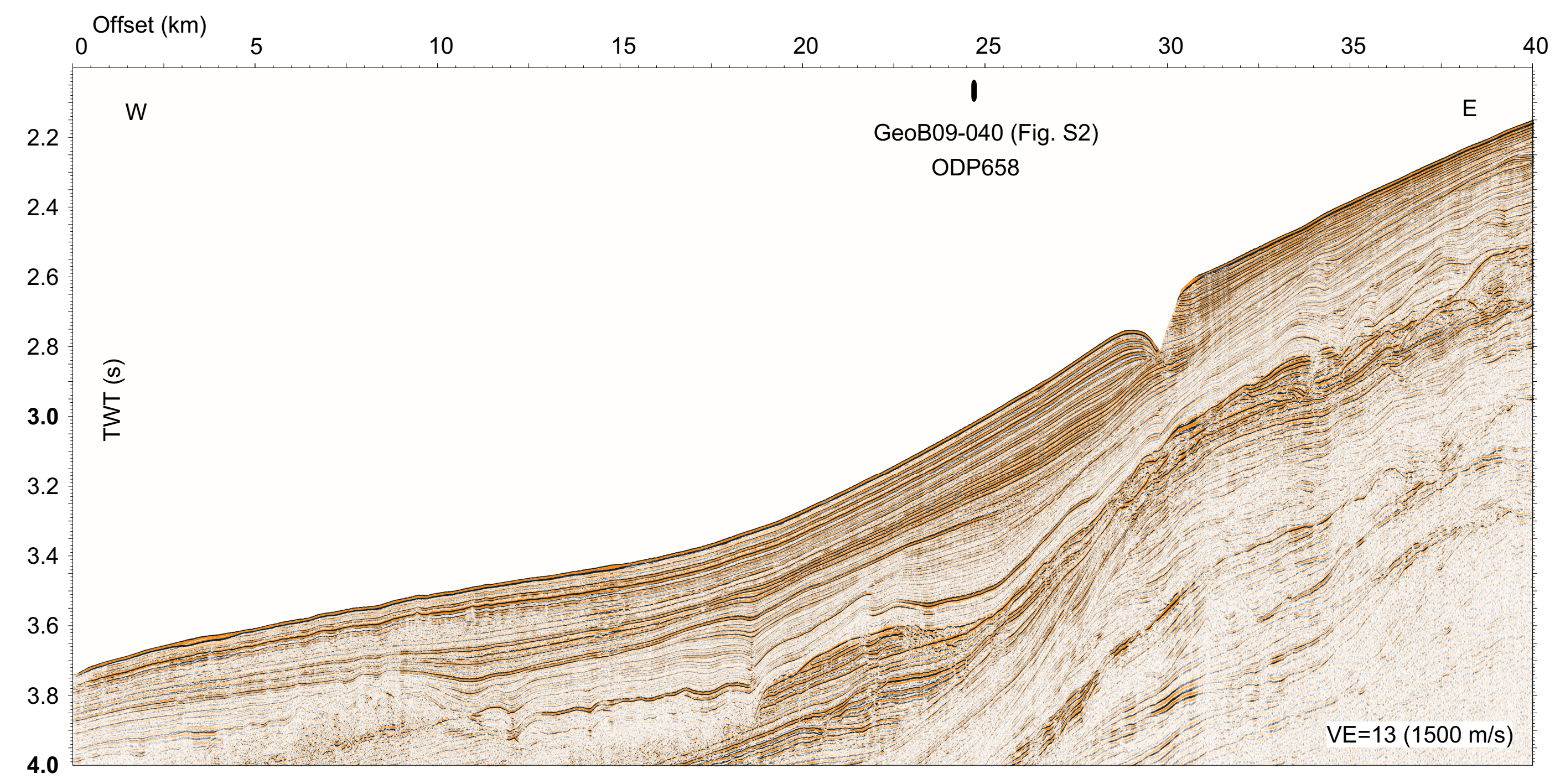



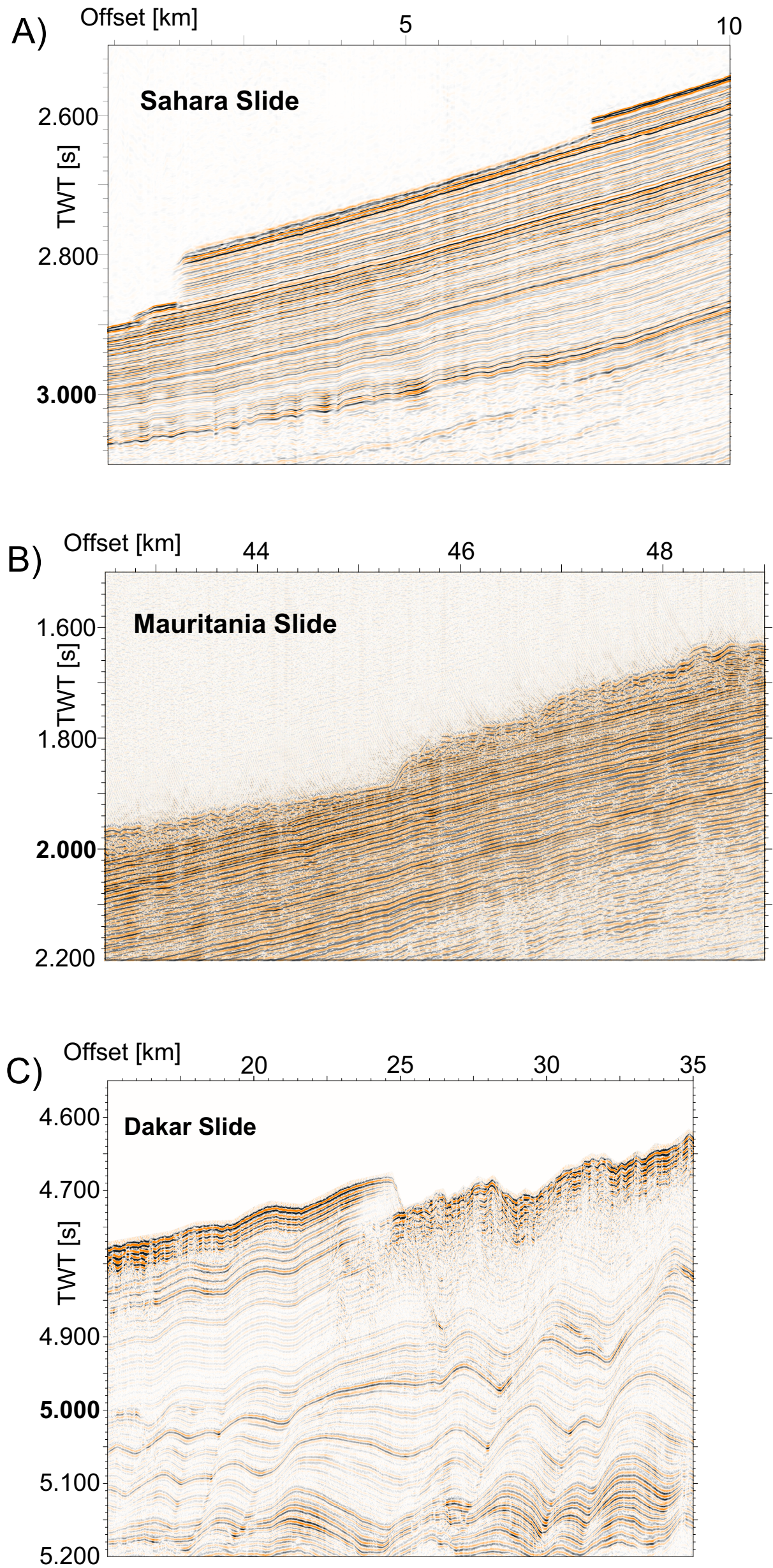